\title{
CONDIÇÃO “NEM NEM” DE EXCLUSÃO E TRABALHO DECENTE PARA JUVENTUDE: PERCEPÇÕES DE CONSTRUTORES DA AGENDA CURITIBA DE TRABALHO DECENTE E GESTORES DO PORTAL DO FUTURO ${ }^{1}$
}

\author{
Roseli Bregantin Barbosa ${ }^{2}$
}

\footnotetext{
- Enviado em 20/01/2016

- Aprovado em 18/02/2016
}

\section{Do tema, objeto e campo da pesquisa}

O fenômeno "nem nem" tomou a ordem do dia com as manifestações de ruas em 2008 na Europa e 2013 no Brasil. Por aqui ganharam a alcunha de "geração nem nem". Jovens que não trabalham, nem estudam. Porém, no Brasil não se trata exatamente de algo novo. É uma condição de desigualdade social permanente ao longo da história brasileira. E ao contrário da situação européia, onde a condição atinge jovens de classe média, aqui são os mais pobres que compõem esse grupo. O tema da pesquisa versa sobre a relação entre a Agenda Curitiba de Trabalho Decente e a condição "nem nem" de exclusão social, sob a percepção dos construtores da Agenda e dos gestores do Portal do Futuro. Tendo como objeto a condição social dos jovens de Curitiba que não estudam, nem trabalham e freqüentam o Portal do Futuro. O campo da pesquisa compreenderá a Secretaria Municipal do Trabalho de Curitiba e os Comitês de Gestão do programa municipal de políticas públicas para jovens "Portal do Futuro".

\footnotetext{
${ }^{1}$ Pesquisa de mestrado em andamento sob a orientação da Professora Doutora Maria Tarcisa da Silva Bega no Programa de Pós-graduação em Sociologia da UFPR.

2 Graduada em Direito pela Fundação Universidade Regional de Blumenau - FURB. Especializada em Direito Empresarial e Societário pelo Complexo de Ensino Superior de Santa Catarina - CESUSC. Mestranda em Sociologia pelo Programa de Pós-Graduação em Sociologia da Universidade Federal do Paraná - UFPR. Endereço eletrônico: roseli.bregantin@hotmail.com
} 
Justificativa:

O estudo em andamento se justifica ante ao fato de a geração "nem nem" ocupar no senso comum um status de realidade enquanto problema social, além do que Curitiba nunca contou com um programa de políticas públicas para jovens na envergadura do programa Portal do Futuro. E ambos os argumentos estão ligados pelas políticas de Trabalho Decente para jovens. O que justifica um estudo acerca das estruturas e conjunturas que levam um jovem à condição "nem nem" em Curitiba, para saber em que medida as agendas políticas de Trabalho Decente propõem ou podem propor soluções que podem atacar esse problema social. Buscamos saber até que ponto e de que forma o programa Portal do Futuro tem adotado essas medidas.

Sobretudo, a pesquisa busca contribuir ampliando o foco sobre os jovens na condição de exclusão social "nem nem", aprofundando o estudo para ir além do dado geral de exclusão. Que eles não tem trabalho remunerado e estão fora do ensino formal já é sabido. Queremos agora entender como eles ocupam seu tempo, quais seus saberes, interesses e perspectivas de futuro. Para então buscar elementos para uma pauta de agenda de política pública que atenda de forma efetiva esse grupo social.

\section{Objetivo geral}

O objetivo geral da pesquisa é definir pautas para uma Agenda Curitiba de Trabalho Decente para Juventude com foco na inclusão social dos jovens "nem nem".

\section{Objetivos específicos}

Dentro dos objetivos específicos do estudo em andamento os principais são: saber quantos são, quem são e qual o perfil socioeconômico dos jovens "nem nem" frequentadores do Portal do Futuro; observar de que modo esses jovens ocupam seu tempo; entender o que eles esperam do futuro; extrair as percepções dos construtores da ACDT e dos gestores do Portal do Futuro acerca da condição "nem nem” de exclusão social.

\section{Pergunta norteadora da pesquisa}

Uma Agenda Curitiba de Trabalho Decente para Juventude é a solução? 


\section{Hipóteses}

As variáveis mais impactantes na condição "nem nem” dos jovens usuários do Portal do Futuro são o gênero e a renda. A maioria deles são mulheres oriundas de famílias de baixa renda.

Os atores protagonistas na construção da ACTD, gestores e os usuários "nem nem" do Portal do Futuro entendem que é necessária a criação de uma Agenda Curitiba do Trabalho Decente para Juventude, porque o mundo do trabalho para jovens têm barreiras sociais distintas das enfrentadas pelos trabalhadores e as demandas juvenis não são adequadamente contempladas na ACTD.

\section{Revisão da literatura}

No estudo em andamento o foco são os aspectos sociológicos de uma política pública de cunho social, bem específica, a política de trabalho para jovens no Brasil, em especial as destinadas aos jovens que não trabalham, nem estudam. Objetivando conhecer a política do Trabalho Decente para jovens, desde sua proposição nas agendas, até a sua implantação, apreendendo e analisando o olhar- acerca da condição de exclusão "nem nem"- dos construtores da ACTD e gestores do programa de políticas públicas para jovens - Portal do Futuro, em Curitiba/PR. Com a finalidade de compreender e analisar em que medida uma Agenda Curitibana de Trabalho Decente para Jovens seria um meio de reduzir esse problema social.

No âmbito do município de Curitiba, a Agenda Curitiba do Trabalho Decente foi lançada em 2012, com clara preocupação em seu texto relativa ao trabalho do jovem. No entanto, apesar da cidade de Curitiba já contar com seu próprio Estatuto da Juventude desde 2013, e deste trazer em si os princípios do Trabalho Decente e contar com um programa de política pública especialmente destinado ao jovem de 15 a 29 anos - Portal do Futuro - neste sendo identificáveis ações de promoção do Trabalho Decente para jovens - ainda não se tem notícia da criação de uma agenda municipal de TD específica para a juventude, nem na esfera municipal, nem na estadual (PR).

Porém, uma questão que não pode deixar de ser analisada, é saber qual a melhor política de trabalho para juventude, se é incentivar o emprego dentro das premissas do TD, ou prolongar o período de transição do jovem para a vida adulta, aumentando seu tempo de escolarização e preparo para enfrentar o mercado, o que aumentaria suas chances de conquistar melhores postos de trabalho (GONZALEZ, 2009). 
Para chegar ao estágio em que se encontram as políticas públicas para o jovem, um longo caminho foi percorrido com ampla participação da sociedade civil, passando por organizações internacionais e nacionais, governamentais e não governamentais. Sendo lideradas por atores coletivos como a Organização Internacional do Trabalho/OIT, Ministério do Trabalho e Emprego, e Secretaria Nacional da Juventude, e protagonizada por juventudes representadas por movimentos sociais, partidos políticos e instituições religiosas. Caminho que pode ser desvendo pelo estudo proposto lançando vistas as possibilidades futuras.

Como representante da OIT no Brasil e disseminadora das diretrizes da ANTD e ANTDJ pelo Brasil a pesquisa conta com os trabalhos de Laís Abramo, que analisa e difunde os principais conceitos e categorias contidos nas agendas de Trabalho Decente brasileiras. Indispensáveis igualmente são as contribuições dos estudos de José Ribeiro (OIT), também muito atuante na implantação das agendas subnacionais do TD pelos estados da Federação brasileira.

Para melhor compreensão do mundo do trabalho e compreensão de como essa realidade começa a se desenhar, o estudo conta com os estudos de Émile Durkheim, Da divisão do trabalho social.

O autor Adalberto Cardoso (2013), profundo estudioso das desigualdades sociais brasileiras é evocado para trabalhar os conceitos de desigualdade social e o de geração "nem nem". Segundo o mesmo, trata-se de um fenômeno midiático cujo conceito foi importado da Europa "ni ni", que não é uma condição nova da juventude, e sim um fenômeno estrutural que ganhou proporções em 2008 na Europa e em 2013 no Brasil. Sendo que lá está relacionado à juventude de classe média, e aqui às camadas mais pobres da população. Ainda trabalhando o conceito de desigualdades sociais contará com os estudos de Ricardo C. Oliveira (2007) em "Redes de Nepotismo como processo de produção e reprodução de Desigualdades", onde o autor faz profunda reflexão sobre a construção do cenário de desigualdades sociais no Brasil, através da reprodução dos capitais familiares, econômicos e culturais.

Nesta seara de igual importância será o trabalho de Ana L. F. Sallas, Maria Tarcisa da Silva Bega (et.al) "Os jovens de Curitiba: desencantos e esperanças, juventude, violência e cidadania”, e das mesmas autoras "Por uma sociologia da Juventude - releituras contemporâneas" (2006). Estudos estes que ajudarão a conhecer um pouco das percepções da realidade social da juventude de Curitiba/PR. 
O Portal do Futuro é um programa de políticas públicas para juventude, instituído pelo Decreto municipal $n^{\circ}$ 452/2013, implementado pelo município de Curitiba em pró de jovens de 15 a 29 anos, com o objetivo de fomentar o protagonismo juvenil, melhorar a qualidade de vida dos jovens e realizar a inclusão social. Para tanto, promove atividades esportivas, culturais, educacionais, tecnológicas e profissionalizantes, além de atividades diferenciadas - como exposições para jovens talentos, acantonamento para alunos da rede pública, troca de experiências com personagens que se destacam em diversas áreas. Estando a escolha das atividades de cada área condicionada à demanda dos jovens usuários dos centros e seus jovens gestores que fazem parte das decisões do Centro. O Portal conta com centros de atividades em várias áreas da cidade, centro e periferias. Cada centro tem um comitê de gestão que é comandado por jovens, que participam de todas as decisões tomadas no centro.

O termo Trabalho Decente foi nomeado pela OIT, que pensou trabalhar com o termo "digno", mas percebeu que acabava por cair na inferência de cunho moral. Optando assim pelo termo "decente" no sentido civilizatório da palavra. Possibilitando a extensão moral do seu antônimo às situações de atentado aos princípios éticos do trabalho humano. O que certamente causa maior impacto.

\section{Metodologia}

A pesquisa é de natureza sociológica, qualitativa interpretativa na perspectiva epistemológica da hermenêutica dialética, nos moldes da sociologia pública de Michael Burawoy (2006), que tem base no materialismo histórico de Karl Marx - para analisar o processo de construção das agendas do Trabalho Decente e do programa de políticas públicas para juventude Portal do Futuro. A perspectiva do materialismo histórico se deve ao fato de que temática se insere entre as ações afirmativas de cunho social, que têm base no conceito de mudança programada a partir de intervenção no aporte de recursos materiais. Estes, entendidos como meios de produção e mobilidade social (concretos e/ou abstratos). O método qualitativo da pesquisa se justifica ante a necessidade de objetivar a subjetividade dos discursos e das falas dos indivíduos a serem conhecidos, observados e interpelados na pesquisa.

Para a objetivação das percepções dos gestores do Portal do Futuro conta com as posturas e conceitos do interacionismo simbólico de Antony Giddens (1984) que afirma que na medida em que a estrutura muda, o indivíduo muda. Verificar-se-á se esta premissa se confirma nas percepções do 
público alvo da pesquisa, e qual o sentido dado às políticas públicas do Trabalho decente por esses jovens.

A pesquisa utiliza-se das técnicas de observação participante, entrevistas narrativas, entrevistas com questões fechadas e/ou abertas, e realização de grupo focal na coleta dos dados (BAUER; GASKELL, 2003).

O campo da pesquisa compreenderá o Conselho Nacional de Juventude - CNJ, a Secretaria Nacional de Juventude - SNJ, bem como a Secretaria Geral Presidência da República e a OIT Organização Internacional do Trabalho, Secretaria Municipal do Trabalho de Curitiba e Comitês de Gestão do programa de políticas públicas municipal Portal do Futuro, por estas instâncias disporem dos materiais necessários para a realização da pesquisa documental e realização de coleta de dados.

\section{REFERÊNCIAS}

BURAWOY. Michael (2006). Por uma sociologia pública. Política \& trabalho Revista de ciências sociais, n. 25 outubro de 2006 - p. 9-50.

CARDOSO, Adalberto (2013). Juventude, Trabalho e Desenvolvimento: elementos para uma agenda de investigação. Caderno CRH, Salvador, v. 26, nº 68, p. 293-314.

CURITIBA. Câmara Municipal. Decreto municipal no 452/2013. Institui o Portal do Futuro. Disponível em: http://www.portaldofuturo.curitiba.pr.gov.br/. Acessado em: 25 de out de 2015.

\section{Estatuto de Juventude de Curitiba. Curitiba: 2013.} http://www.infojovem.org.br/blog/2013/02/01/estatuto-juventude-curitiba-2013/. Acessado em: 30 de jun de 2015.

GASKELL, George (2003). Entrevistas individuais e grupais. In: JOVCHELOVITCH, Sandra; BAUER, Martin W. Pesquisa qualitativa com texto, imagem e som. Petrópolis: Vozes.

GIDDENS, Anthony (1984). A constituição da sociedade. São Paulo: Martins Fontes.

GONZALEZ, Roberto (2009). Políticas de Empregos para Jovens: Entrar no mercado de trabalho é a saída? In: ANDRADE, Carla Coelho; AQUINO, Luseni M. C. de; CASTRO, Jorge A. de; Juventude e políticas sociais no Brasil. Brasília: Ipea.

OLIVEIRA. Ricardo C (2007). Redes de Nepotismo como processo de produção e reprodução de Desigualdades. $\quad$ ANPOCS: 2009. http://www.academia.edu/227870/Redes_de_Nepotismo_como_processo_de_produ\%C3\%A7\%C3 \%A3o_e reprodu\%C3\%A7\%C3\%A3o_de desigualdades. Acessado em: 20 de outubro de 2015.

SAllAS, Ana L. F.; BEGA, Maria Tarcisa S. (2006). Por uma Sociologia da Juventude releituras contemporâneas. Disponível em: https://periodicos.ufsc.br/index.php/politica/article/viewFile/1803/1562. Acessado em 10 de julho. 2015. 